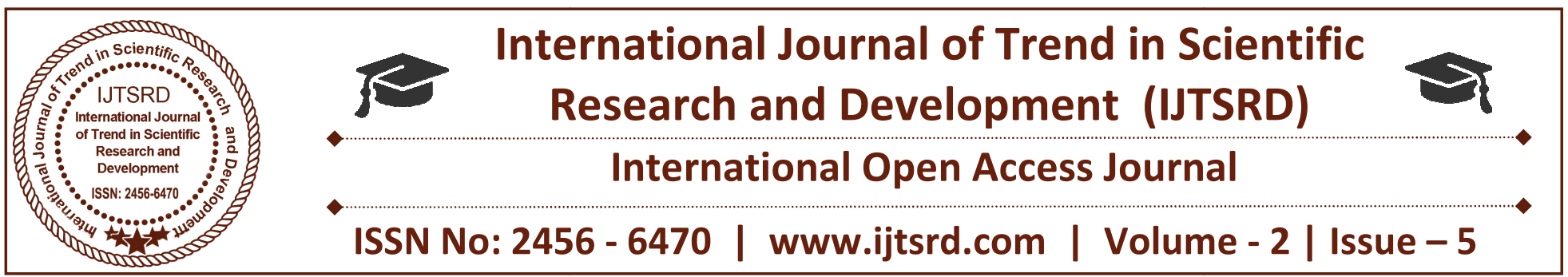

\title{
Tablet Computers
}

\author{
Matthew N. O. Sadiku', Sarhan M. Musa', Nana K. Ampah ${ }^{2}$ \\ ${ }^{1}$ Professor, ${ }^{2}$ Adjunct Faculty \\ ${ }^{1}$ Roy G. Perry College of Engineering, A \& M University, Prairie View, TX 77446, United States \\ ${ }^{2}$ Lone Star College, Kingwood, TX 77339, United States
}

\begin{abstract}
Tablet computers are touch screens. They are easier to use for older people and people with disabilities. They have been proven to be very useful in the educational system because of their portability, flexibility, ease of note taking, convenient access, and multiple applications. Tablet PCs along with wireless technology can be used to change the dynamics of classroom instruction. This paper provides a brief introduction to tablet computers.
\end{abstract}

Key Words: tablet computers, tablets, pen-computers

\section{INTRODUCTION}

We are experiencing a pattern of change in computing device paradigm. There is transition from mainframes to minicomputers in the 1970 s, to PCs in the 1980 s, and recently to portable computers. The trend is towards smaller and more portable computing devices [1].

A tablet computer (tablet for short) is a portable personal computer that typically uses a mobile operating system. It runs on apps in substitution for software. It lacks physical keyboard. The touch screen liquid-crystal display (LCD) is operated by touching instead of the mouse. I Pad, released by Apple in 2010, was the first commercially successful tablet. The release featured 9.7-inch, 1024 by 768 displays with 16-, 32-, and 64-GB capacities. I Pad is regarded as a revolutionary, disruptive device. It enables users to view TV programs. In 2008, the first type of Android-based tablets appeared. Other tablets include the BlackBerry, Nokia 770, Galaxy, and Rand tablet [2]. It is interesting to note that the tablet concept was popularized by Microsoft, a software giant, not by hardware manufacturers.
Tablet PCs are basically laptops with added functionality of using a stylus too directly on the touch screen. This functionality enables table PCs to suitable in solving problems that need sketches, diagrams, and mathematical formulas.

\section{TYPES OF TABLETS}

There are three types of tablets running on different operating systems [3]:

$>$ Windows-based tablets

$>$ Apply-based tablets

$>$ Android tablets

They have their unique advantages and disadvantages. They have a touch screen, which can be used with a pen or fingers. They all run applications or apps. Apps (software packages) that do not come preinstalled in the tablets can be obtained through online or apps stores. As of July 2011, Apple noted that more than 15 billion apps were used on I Pad, I Phone, and iPod Touch. Other organizations have started to take advantage of this technology by developing their own apps. Local TV stations are now using apps to provide news to mobile audience [4].

\section{APPLICATIONS}

Tablet owners use the device for entertainment, playing games, and searching for news and information. The tablet computer is used in conjunction with electronic health information resources. Although the healthcare industry was enthusiastic about the features and abilities of tablet computer, yet slow in its adoption. This is primarily due to issues including security and privacy of patient information. It is found that utilizing tablet computers 
increases provider productivity, improves

communication with patients, and enhances the process of care [5]. The pharmaceutical industry followed suit by developing apps that offer useful information about the drugs to doctors, nurses, and patients. The tablet has also started to enter the educational system. Tablet PCs along with wireless technology can be used to change the dynamics of classroom instruction. This is reported to have significant impact on student performance in problemsolving intensive courses [6].

\section{BENEFITS AND CHALLENGES}

Depending on the care environment, mobile tablets may provide significant benefits of personalization, portability, and productivity. The tablets are helping to revolutionize the healthcare industry since they have the potential to deliver simple, inexpensive, effective, and personalized solutions. When used in healthcare, tablets avoid cumbersome and error prone human data entry. They provide rapid access to information wherever it is needed [7].

The education system has historically been resistant to change due to technology. This is partly due to bureaucracy in the system. This is also due to the fact that when a new technology such as tablet computer is introduced, students, teachers, and administrators are under pressure to adapt to the changes [8].

Tablets are limited in terms of performance, usability, and commercial success. Since tablets are touch screen devices, you may not be able to use them if you have shaky hands due to disability.

\section{CONCLUSION}

Today, the computing device paradigm is witnessing a transition from notebooks to touch screen tablets. Support for integrating technology into the curriculum comes from policymakers, economists, and educational administrators. Specifically, mobile devices are more motivating and engaging than traditional classroom tools. Tablets can be used anywhere, anytime and can foster individualized learning [9]. As technology is integrated into classroom, educators are all levels should seriously consider using table PCs over laptops and desktops in their classroom.

\section{REFERENCES}

1. M. N. Cortimiglia, A. G. Frank, and L. Seben, "Tablets: The next disruptive computing technology," IT Pro, May/June 2013, pp. 18-25.
2. "Tablet computer," Wikipedia, the free encyclopedia

https://en.wikipedia.org/wiki/Tablet_computer

3. "Tablet computer,"

https://www.abilitynet.org.uk/sites/abilitynet.org.u k/files/Tablet\%20computers.pdf

4. C. F. Greer and D. A. Ferguson, "Tablet computers and traditional television (TV) viewing: Is the I Pad replacing TV?" Convergence: The International Journal of Research into New Media Technologies, vol. 21, no. 2, 2015, pp. 244-256.

5. B. Schooley et al., "Impacts of mobile tablet computing on provider productivity, communications, and the process of care," International Journal of Medical Informatics, vol. 88, 2016, pp. 62-70.

6. A. G. Enriquez, "Enhancing student performance using table computers," College Teaching, vol. 58, no. 3,2010 , pp. 77-84.

7. R. Adil, "The usage of tablets in the healthcare industry,"

https://www.healthcareitnews.com/blog/usagetablets-healthcare-industry

8. T. Long, W. Liang, and S. Yu, "A study of the tablet computer's application in 1-12 schools in China," International Journal of Education and Development Using Information and Communication Technology, vol. 9, no. 3, 2013, pp. 61-70.

9. C. Blackwell, "Teacher practices with mobile technology integrating table computers into the early childhood classroom," Journal of Education Research, vol. 7, no. 4, 2014.

\section{AUTHORS}

\section{Matthew N.O. Sadiku}

Is a professor in the Department of Electrical and Computer Engineering at Prairie View A\&M University, Prairie View, Texas. He is the author of several books and papers. His areas of research interests include computational electromagnetic and computer networks. He is a fellow of IEEE.

\section{Nana K. Ampah}

Is an adjunct faculty at Lone Star College, Kingwood, Texas. His research interests include enterprise network security, power optimization, smart grid, and renewable energy. He is a member of IEEE.

\section{Sarhan M. Musa}

Is a professor in the Department of Engineering Technology at Prairie View A\&M University, Texas. He has been the director of Prairie View Networking 
Academy, Texas, since 2004. He is an LTD Sprint and Boeing We liver Fellow.

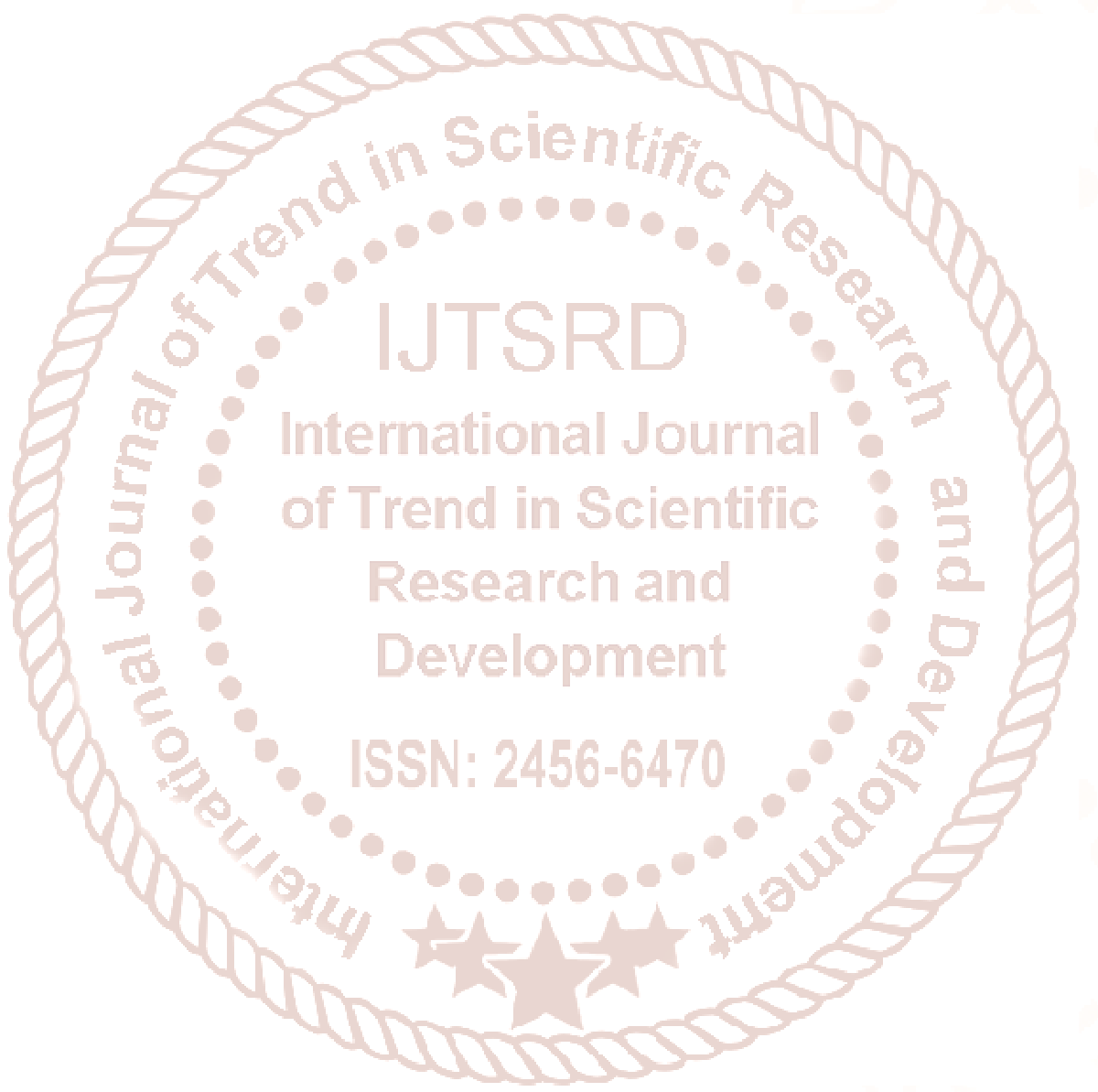

